\title{
Estratégias de controle de braquiárias Urochloa spp. na formação de povoamento para restauração florestal
}

\author{
Control strategies of Urochloa spp. in the formation of forest restoration
}

\author{
Flávio Augusto Monteiro dos Santos ${ }^{\mathrm{I}}$, Paulo Sérgio dos Santos Leles ${ }^{\mathrm{II}}$, \\ Alexander da Silva Resende ${ }^{\mathrm{III}}$, Daniel Ferreira do Nascimento ${ }^{\text {IV }}$, \\ Gabriel Rocha dos Santos ${ }^{\mathrm{V}}$
}

\begin{abstract}
Resumo
A restauração florestal em áreas de pastagens, dominadas por Urochloa spp. (braquiárias), apresenta custo relativamente elevado, principalmente pela dificuldade de controle dessa planta infestante. O objetivo deste trabalho foi determinar a forma de controle de braquiárias mais eficiente para a formação de povoamento para restauração florestal. Foram comparadas quatro estratégias para controle de braquiária em área de restauração florestal no município de Bom Jardim - RJ: T1 - capina em faixas nas linhas de plantio e roçadas nas entrelinhas; T2 - capina em faixas nas linhas de plantio e aplicações do herbicida glyphosate $\left(1,44 \mathrm{~kg}\right.$ i.a. ha- $\left.\mathrm{a}^{-1}\right)$ nas entrelinhas; T3 - capina em área total e consórcio com leguminosas herbáceas fixadoras de nitrogênio; T4 - capina em faixas nas linhas de plantio, roçadas e consórcio com eucalipto nas entrelinhas. Avaliou-se o crescimento em altura, diâmetro no nível do solo e diâmetro de copa de dez espécies arbóreas em diferentes idades, bem como todos os custos envolvidos na aplicação e manutenção de cada tratamento, até 30 meses após o plantio. Em todas as épocas de avaliação, as plantas florestais apresentaram média de crescimento significativamente superior em altura e em diâmetro nos tratamentos de consórcio com leguminosas e aplicação de glyphosate (T3 e T2). Aos 24 meses após o plantio, a copa das árvores implantadas já recobria $80 \%$ a $90 \%$ da área da unidade experimental nesses tratamentos. Entretanto, o custo de manutenção do T3 foi quase o dobro das unidades de T1 e o custo deste último foi quase três vezes superior das unidades submetidas a T2. O consórcio de eucalipto nas entrelinhas de plantio não prejudicou, mas não beneficiou o crescimento das espécies nativas. O controle químico e o consórcio com leguminosas herbáceas podem ser apontados como alternativas eficazes para controle da braquiária dessa área, antecipando a formação dos povoamentos e resultando em economia de recursos.
\end{abstract}

Palavras-chave: Controle de plantas daninhas; Sistemas agrossilviculturais; Controle químico; Mata Atlântica

Engenheiro Florestal, MSc., Doutorando do Programa de Pós-Graduação em Ciências Ambientais e Florestais, Instituto de Florestas, Universidade Federal Rural do Rio de Janeiro, Rodovia BR 465, Km 07, s/n Zona Rural, CEP 23890-000, Seropédica (RJ), Brasil. monteiro.flaviosantos@gmail.com (ORCID: 0000-0001-8757-5082)

II Engenheiro Florestal, Dr., Professor do Departamento de Silvicultura, Instituto de Florestas, Universidade Federal Rural do Rio de Janeiro, Rodovia BR 465, Km 07, s/n Zona Rural, CEP 23890-000, Seropédica (RJ), Brasil. pleles@ufrri.br (ORCID: 0000-0002-8393-6095)

III Engenheiro Florestal, Dr., Pesquisador da Embrapa Agrobiologia. Rodovia BR 465, Km 07, s/n Zona Rural, CEP 23897-970. Seropédica (RJ), Brasil. alexander.resende@embrapa.br (ORCID: 0000-0002-1433-9203)

IV Engenheiro Florestal, Empresa Prumo Logística S.A., Via 5 Projetada, CEP 28200-000, Barra de São João (RJ), Brasil. daniel.nascimento@ prumologistica.com.br (ORCID: 0000-0002-6122-2091)

Engenheiro Florestal, MSc., Instituto de Florestas, Universidade Federal Rural do Rio de Janeiro, Rodovia BR 465, Km 07, s/n Zona Rural, CEP 23890-000, Seropédica (RJ), Brasil. grocha.santos@hotmail.com (ORCID: 0000-0003-1699-230X) 


\begin{abstract}
Forest restoration in pastures dominated by Urochloa spp. (brachiaria) shows relatively high cost, mainly by the difficulty of controlling this weed. The objective of this work was to determine the most efficient brachyria control for forest restoration formation. Four different strategies for brachiaria control in the forest restoration area were compared in the city of Bom Jardim, Rio de Janeiro state: T1 weeding in strips in the planting lines and mowed between the lines; T2 weeding in strips in the planting lines and applications of glyphosate $\left(1.44 \mathrm{~kg}\right.$ i.a. $\left.\mathrm{ha}^{-1}\right)$ between the lines; $\mathrm{T} 3$ - weeding in total area and consortium with herbaceous legumes nitrogen-fixing; T4 - weeding in strips in the planting lines, mowing and consortium with eucalyptus between the lines. The growth in height, the diameter at ground level and the diameter of the top of ten forest species at different ages were evaluated, as well as all costs involved in the application and maintenance of each treatment, up to 30 months after planting. In every age of valuation, forest plants showed significantly higher average growth in height and diameter at the ground level in the treatment of consortium with herbaceous legumes and application of glyphosate. At 24 months after planting, the top of the trees that were introduced had already covered $80 \%$ to $90 \%$ of the area of experimental unit that received the T3 (legumes) and T2 (Glyphosate) treatments, respectively. However, the maintenance cost of the T3 was almost double the T1 units and the cost of the latter was almost three times higher than the units analyzed for T2. As a general rule, eucalyptus consortium between the lines of planting did not harm, but also did not benefit the growth of the native species planted up to 30 months after planting. Chemical control and consortium with herbaceous legumes can be pointed as effective alternatives to control the brachiaria of this area, anticipating the formation of stands and resulting in resource savings.
\end{abstract}

Keywords: Weed control; Agrossilviculturais systems; Chemical control; Atlantic Forest

\title{
Introdução
}

As áreas destinadas à restauração florestal encontram-se altamente descaracterizadas do ponto de vista da sua composição de espécies nativas, representadas, em sua maior parte, por pastagens degradadas (NAVE et al., 2009). Nesse cenário, a restauração passa a apresentar um alto custo (NAVE et al., 2009; LELES; OLIVEIRA NETO; ALONSO, 2015), principalmente devido à necessidade de controle permanente de plantas daninhas agressivas como as dos gêneros Urochloa (braquiárias) e Panicum (capim-colonião), frequentemente encontrados nas pastagens da região sudeste do Brasil (SILVA et al., 2009a). Segundo Leles, Oliveira Neto e Alonso (2015), o custo com o controle de plantas daninhas pode representar até $60 \%$ do custo total de projetos de recomposição florestal, na região da baixada fluminense - RJ, onde há infestação dessas gramíneas. Diferentes métodos de controle das espécies desses dois gêneros, aliadas à aplicação de diferentes técnicas silviculturais têm sido testadas, e os relatos demonstram a influência do controle das plantas daninhas no tempo de formação dos povoamentos de restauração florestal, bem como no custo total desses projetos (MARTINS, 2011; CÉSAR et al., 2013; SANTOS, 2013; LELES; OLIVEIRA NETO; ALONSO, 2015).

Dentre as alternativas de controle da infestação de plantas daninhas encontra-se o consórcio das espécies arbóreas de restauração com leguminosas herbáceo-arbustivas fixadoras de nitrogênio com potencial para a rápida cobertura e adubação do solo (MARTINS, 2011; SANTOS, 2013). Segundo essa estratégia, as leguminosas favorecem o rápido crescimento das arbóreas devido à cobertura do solo, diminuindo a infestação de braquiária e assim reduzindo o tempo necessário para o fechamento da copa das árvores. O fechamento das copas reduz a incidência de radiação solar direta sobre o solo, tornando o ambiente pouco favorável à proliferação de gramíneas heliófilas. A antecipação do fechamento das copas, ou formação do povoamento, resultará na economia de recursos humanos e financeiros com a manutenção, com impacto direto e significativo no custo total das ações de restauração florestal (SANTOS, 2013).

Destaca-se também o controle pelo método químico, através da aplicação de herbicidas sistêmicos e de baixa toxicidade, prática cada vez mais comum na condução de povoamentos de restauração florestal. A principal prerrogativa associada a esse método é o baixo custo para controle das plantas daninhas (BRANCALION et al., 2009). O emprego do controle químico ainda 
esbarra na ausência de uma legislação que regulamente o uso desses produtos na restauração florestal (MARTINS, 2011).

Outra estratégia com potencial de auxiliar no controle das plantas daninhas é o consórcio com árvores de rápido crescimento, como as espécies do gênero Eucalyptus, capazes de formar um dossel rápido, diminuindo a incidência de radiação luminosa que chega à superfície do solo, limitando o crescimento das gramíneas heliófilas (SILVA, 2013). Além disso, essa estratégia apresenta a possibilidade de gerar renda ao produtor, a partir do uso da madeira na propriedade ou para a sua comercialização.

Sendo assim, este trabalho objetivou indicar o método de controle de Urochloa spp., entre quatro estratégias avaliadas, através do crescimento conjunto de dez espécies florestais nativas da Mata Atlântica e os custos de manutenção, em área de restauração florestal no município de Bom Jardim - RJ.

\section{Material e métodos}

O experimento foi implantado em novembro de 2011, em área experimental que totaliza 9,5 ha da Pequena Central Hidrelétrica (PCH) Santa Rosa II, no município de Bom Jardim, região serrana do estado do Rio de Janeiro. O município apresenta altitude média de 530 metros, clima do tipo Aw (tropical chuvoso com inverno seco e verão chuvoso) com temperatura média anual de $22,0^{\circ} \mathrm{C}$, com mínima de $16,0^{\circ} \mathrm{C}$ no mês de julho e máxima de $28,0^{\circ} \mathrm{C}$ no mês de fevereiro e precipitação média anual de 1.536 mm (AGÊNCIA NACIONAL DE ÁGUAS, 2016). Predominam na região solos do tipo Latossolo Vermelho Amarelo Distrófico e a fitofisionomia predominante é de floresta ombrófila densa.

Para alocação das unidades experimentais, foi selecionada área contínua, com relevo forte-ondulado, dominada por Urochloa brizantha (Stapf) Webster cv. Marandu e U. decumbens (Stapf.) Webster. O preparo da área consistiu na roçada em área total, com auxílio de roçadeiras laterais; demarcação dos berços de plantio em espaçamento de 3,2 x 1,8 metros; e capina em faixas com 1,20 metros na linha de plantio. Em seguida, foram abertos os berços de plantio com $30 \times 30 \times 30 \mathrm{~cm}$, adubados com 120 gramas de N-P-K (03-24-04) por berço na época do plantio. Foi iniciado o controle de formigas-cortadeiras com iscas formicidas granuladas na área de plantio e em áreas vizinhas, logo após a roçada.

As mudas utilizadas foram produzidas em sacos plásticos de 9 x $20 \mathrm{~cm}$ (diâmetro x altura) previamente selecionadas em viveiro, de forma que os indivíduos de cada espécie apresentavam porte semelhante e com bom aspecto fitossanitário.

As espécies utilizadas foram Anadenanthera macrocarpa (Benth.) Brenan, Cordia trichotoma (Vell.) Arrab. ex Steud., Cytharexyllum myrianthum Cham., Enterolobium contortisiliquum (Vell.), Guarea guidonia (L.) Sleumer, Peltophorum dubium(Springer.) Taub. Schizolobium parahyba (Vell.) S.F. Blake, Schinus terebinthifolius Raddi, Senna multijuga (Rich.) Irwin et Barn. e Tibouchina granulosa Cogn. Ambas as espécies são comumente utilizadas em projetos de restauração florestal do entorno da PCH Santa Rosa e na região.

Adotou-se o delineamento em blocos casualizados (DBC), com três repetições de cada tratamento, totalizando 12 unidades experimentais. Em cada uma delas foram utilizados pelo menos 5 indivíduos de cada uma das 10 espécies arbóreas. A sequência de distribuição das espécies entre os berços de plantio foi rigorosamente a mesma, de forma que cada unidade experimental apresentava a mesma ordem de espécies nas linhas e entrelinhas de plantio, como forma de padronizar possíveis efeitos relacionados ao crescimento conjunto das espécies florestais implantadas.

Dois meses após o plantio, os tratamentos de controle foram aplicados, seguindo as operações de manutenção, quando necessárias, até os 30 meses após o plantio, conforme apresentado na Tabela 1. 


\section{Tabela 1 - Atividades de manutenção sob quatro estratégias de controle de Urochloa spp. na área de restauração florestal, no município de Bom Jardim - RJ}

Table 1 - Maintenance activities under four Urochloa spp. control strategies, in the forest restoration area in the city of Bom Jardim - RJ state

\begin{tabular}{|c|c|}
\hline Tratamento & Atividades de manutenção \\
\hline $\begin{array}{l}\text { T1 } \\
\text { (Roçada) }\end{array}$ & $\begin{array}{l}\text { Limpeza das faixas por capina manual e roçada com roçadeira nas entrelinhas, sempre que a } \\
\text { braquiária atingisse altura média de } 25 \mathrm{~cm} \text {. Adubações de cobertura N-P-K (20-05-20) aos 6, } \\
12 \text { e } 18 \text { meses, em doses de } 50 \mathrm{~g}, 50 \mathrm{~g} \text { e } 120 \mathrm{~g} \text {, respectivamente. }\end{array}$ \\
\hline $\begin{array}{l}\text { T2 } \\
\text { (Glyphosate) }\end{array}$ & $\begin{array}{l}\text { Limpeza das faixas de plantio com capina manual e aplicação, com pulverizador costal, de } \\
\text { aplicação de glyphosate na dose de } 1,44 \mathrm{~kg} \text { i.a. ha-1 nas entrelinhas, sempre que a braquiária } \\
\text { atingisse altura média de } 15 \mathrm{~cm} \text { e distribuídos em mais de } 30 \% \text { da unidade experimental. Este } \\
\text { herbicida foi selecionado por exercer controle efetivo sobre a maioria das espécies relatadas } \\
\text { como daninhas na área florestal (MACHADO et al., 2011) e esta intensidade de infestação foi } \\
\text { adotada como limite viável para aplicação do controle químico. Abaixo desta incidência, foi } \\
\text { realizada a capina para limpeza da área. Adubações de cobertura N-P-K (20-05-20) aos } 6 \text {, } 12 \text { e } \\
18 \text { meses, em doses de } 50 \mathrm{~g}, 50 \mathrm{~g} \text { e } 120 \mathrm{~g} \text {, respectivamente. }\end{array}$ \\
\hline $\begin{array}{l}\text { T3 } \\
\text { (Leguminosas) }\end{array}$ & $\begin{array}{l}\text { Capina em área total da braquiária. Abertura de pequenas covas, semeadura de Crotalaria } \\
\text { juncea L. }\left(5 \mathrm{~kg}^{-h^{-1}}\right) \text {. Após o ciclo dessa cultura, realizada nova abertura de covetas e } \\
\text { semeadura de Canavalia ensiformis DC. }\left(70 \mathrm{~kg} \cdot \mathrm{ha}^{-1}\right) \text { em consórcio com Cajanus cajan } \\
\text { (L.) Millsp. }\left(2 \mathrm{~kg} \cdot \mathrm{ka}^{-1}\right) \text {. O manejo previu sempre a manutenção do solo coberto com as } \\
\text { leguminosas herbáceas e limpeza da área com braquiária por capina. Não foi realizada } \\
\text { adubação de cobertura das arbóreas neste tratamento. }\end{array}$ \\
\hline $\begin{array}{l}\text { T4 } \\
\text { (Eucalipto) }\end{array}$ & $\begin{array}{c}\text { Limpeza das faixas por capina manual e roçada nas entrelinhas, sempre que o capim } \\
\text { braquiária atingisse altura média de } 25 \mathrm{~cm} \text {. Coroamento e plantio mudas do clone GG100 } \\
\text { de Eucalyptus urograndis x E. grandis, distanciado } 3,5 \mathrm{~m} \text { entre si, no meio das entrelinhas das } \\
\text { espécies nativas. Coroamento e adubação de cobertura nas plantas de eucalipto, com NPK } \\
(20-05-20) \text {. Adubações de cobertura das nativas com N-P-K }(20-05-20) \text { aos } 6,12 \text { e } 18 \text { meses, em } \\
\text { doses de } 50 \mathrm{~g}, 50 \mathrm{~g} \text { e } 120 \mathrm{~g} \text {, respectivamente. }\end{array}$ \\
\hline
\end{tabular}

Fonte: Autores (2017)

Durante a fase de implantação dos tratamentos, realizou-se também a operação de replantio, utilizando mudas da mesma espécie, a fim de respeitar o arranjo original das espécies nas unidades experimentais.

Foram realizadas avaliações do crescimento das espécies florestais, com medições da altura da parte aérea aos 6, 18, 24 e 30 meses após o plantio; diâmetro ao nível do solo (DNS) aos 18 e 30 meses após o plantio e comprimento de copa longitudinal $\left(D_{1}\right)$ e transversal à linha de plantio $\left(D_{2}\right)$ para cada indivíduo aos 24 e 30 meses. As medições de altura foram executadas com auxílio de vara graduada. Para o diâmetro utilizou-se paquímetro digital e para diâmetro de copa, trena.

Com os dados de comprimentos da copa, determinou-se a cobertura do solo pela projeção perpendicular da copa das espécies arbóreas implantadas (GREIG-SMITH, 1983), aplicando os métodos adaptados de grau de cobertura e intercessão de linhas (MELO et al., 2007). O método do grau de cobertura consiste na relação entre a área de copa dos indivíduos arbóreos e a área total da unidade experimental (MÜELLER; ELLEMBERG, 1974), segundo a relação:

$$
G=100 *\left(\frac{\sum a i}{A}\right)
$$

Em que: $\mathrm{G}=$ grau de cobertura (\%); $\mathrm{A}=$ área do tratamento $\left(\mathrm{m}^{2}\right)$ e $\mathrm{a}_{\mathrm{i}}=$ área de projeção da copa do indivíduo. 
Calculado segundo a relação:

$a_{i}=\left(\frac{\pi^{*} D 1 * D 2}{4}\right)$

Em que: $\mathrm{D}_{1}=$ comprimento longitudinal da copa do indivíduo em relação à linha de plantio $(\mathrm{m}) ; \mathrm{D}_{2}=$ comprimento transversal da copa do indivíduo em relação à linha de plantio (m) e $\pi=3,1415$.

O método de intercessão de linhas relaciona o comprimento das copas das espécies implantadas com o comprimento da linha de plantio (CANFIELD, 1941), conforme a relação:

$$
I=100 *\left(\frac{\sum D 1}{C}\right)
$$

Em que: I= Intercessão de linhas (\%); $\mathrm{D}_{1}=$ comprimento longitudinal da copa do indivíduo $(\mathrm{m}) ; \mathrm{C}=$ comprimento total da linha de plantio $(\mathrm{m})$.

Foram avaliados também os custos relacionados à utilização de cada método de controle de braquiária: implantação do método, incluindo a aquisição de insumos (adubo, mudas e sementes), atividade de semeadura/plantio e aplicação de adubo, bem como todas as atividades de manutenção realizadas em cada tratamento. Para isso, todas as atividades realizadas em cada tratamento foram listadas e cronometradas.

Para cálculo dos custos totais de cada tratamento até os 30 meses após o plantio, foi considerando o custo de homem.dia de $\mathrm{R} \$ 100,00$. O custo dos insumos utilizados foi determinado a partir da média de preços desses produtos cotados em algumas lojas de produtos agrícolas da região serrana do estado do Rio de Janeiro e zona da Mata de Minas Gerais. Com base na intensidade, duração e preço de mão de obra e dos insumos foi estimado o custo médio para formação, por hectare, adotando as quatro estratégias de controle de Urochloa spp, até 30 meses após o plantio das espécies nativas.

Os dados biométricos foram submetidos à verificação de normalidade e homogeneidade, não sendo necessário realizar a transformação dos mesmos. Em seguida, procedeu-se à análise de variância para os dados de crescimento em altura aos 6, 18 e 30 meses; DNS aos 18 e 30 meses, bem como para os indicadores de cobertura por copas aos 24 e 30 meses. Quando detectadas diferenças significativas entre os tratamentos, as médias foram comparadas pelo teste de Tukey, a $95 \%$ de probabilidade.

\section{Resultados e discussão}

\section{Crescimento das espécies florestais}

Constata-se pela Figura 1 que, em média, as plantas do conjunto de espécies florestais apresentaram crescimento significativamente superior em altura nos tratamentos de consórcio com as leguminosas herbáceas fixadoras de nitrogênio e aplicações de glyphosate. Esse comportamento foi observado em todas as idades avaliadas, desde a primeira avaliação (4 meses após a aplicação dos tratamentos), até 30 meses após o plantio. Por essas duas metodologias, o manejo foi pautado na eliminação ou substancial redução das populações de Urochloa spp. na área do povoamento, condicionando um menor período de convivência das arbóreas com as plantas daninhas, principalmente no período posterior ao plantio, quando as espécies implantadas são mais sensíveis à interferência causada pelas plantas daninhas (TOLEDO et al., 2000; TAROUCO et al., 2009; LONDERO et al., 2012). 
Figura 1 - Crescimento médio semestral em altura, de 6 aos 30 meses após o plantio, para o conjunto de dez espécies florestais, em resposta a quatro estratégias de controle de Urochloa spp. em área de reflorestamento, município de Bom Jardim - RJ. Para cada idade, médias seguidas pela mesma letra não diferem pelo teste de Tukey $(P \geq 95 \%)$

Figure 1 - Half-yearly average growth in height of 6 to 30 months after planting, for all ten forest species in response to four Urochloa spp control strategies. in reforestation area, the city of Bom Jardim - RJ state. For each age, averages followed by the same letter do not differ by

Tukey test $(\mathrm{P} \geq 95 \%)$

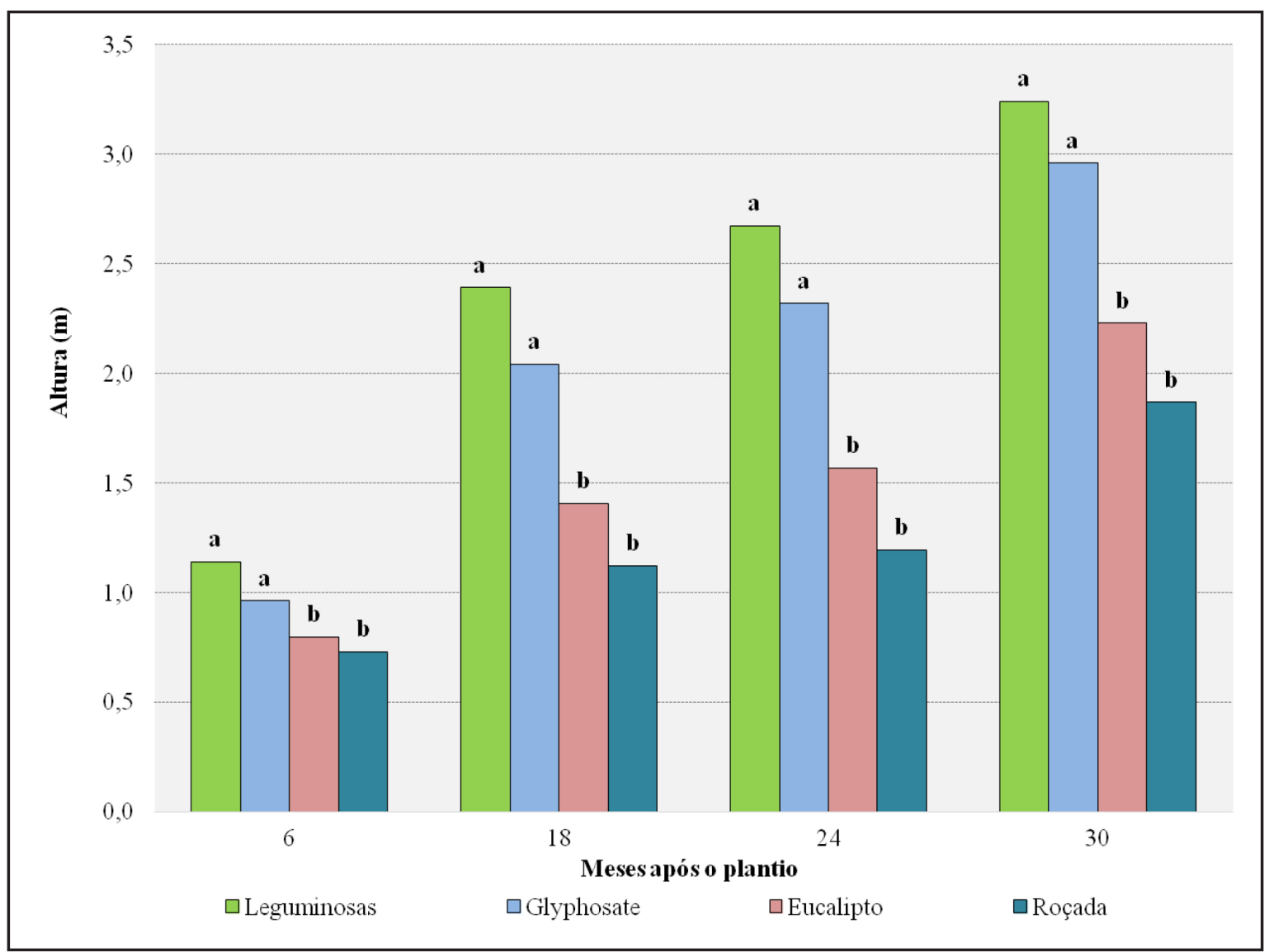

Fonte: Autores (2017)

A eliminação das plantas de braquiária das unidades experimentais do consórcio (T3) e de capina química (T2) não só garante maior oferta de fatores de crescimento como água, luz e nutrientes para as arbóreas implantadas, como também evita a possível ação danosa de compostos alelopáticos liberados pelas plantas de braquiária (PITELLI, 1987; SOUZA et al., 2003) sobre as espécies florestais. Nos outros dois tratamentos, o manejo foi a eliminação pontual das plantas daninhas por meio da capina em faixa com 1,20 metros de largura e roçada nas entrelinhas. Possivelmente, a largura da faixa capinada não foi suficiente para a completa eliminação dos efeitos da matocompetição, diminuindo o ritmo de crescimento das espécies florestais. Maciel et al. (2011) demonstraram que o coroamento deve apresentar diâmetro mínimo de 2,0 metros para não afetar o crescimento de Inga fagifolia e de Schinus terebinthifolius, até 14 meses após o plantio.

Comparando o crescimento em altura das plantas arbóreas de restauração consorciadas com eucalipto (T4) com aquelas que não cresceram em consórcio (T1), conforme mostrado na Figura 1 , constata-se que o eucalipto não prejudicou o crescimento das espécies florestais nativas. Essa constatação é particularmente interessante, quando é considerada a possibilidade de produção de 
madeira de eucalipto, para uso na propriedade rural ou mesmo para comercialização, gerando renda para o pequeno produtor, e contribuindo para diminuir a pressão sobre as florestas naturais. Essa alternativa é sustentada pela Lei $\mathrm{N}^{\circ} 12.651$ de 25 de maio de 2012, alterada pela Lei Federal $\mathrm{n}^{\circ} 12.727$ de 17 de outubro de 2012, que, em seu artigo 61-A parágrafo 13 - inciso IV e artigo 66, versa que a área de preservação permanente e reserva legal poderão ser recuperadas com a utilização de espécies exóticas, desde que o plantio seja combinado com espécies nativas e as espécies exóticas não excedam a $50 \%$ da área total a ser recuperada.

Ao analisar o crescimento em diâmetro ao nível do solo, para o conjunto das dez espécies florestais, apresentado na Figura 2, observa-se o mesmo padrão de resposta em altura. As árvores cresceram mais quando em consórcio com leguminosas e também no tratamento que foi realizado o controle de plantas daninhas com glyphosate. Da mesma forma que para a altura, não houve diferença significativa para o crescimento em diâmetro das plantas no tratamento de consórcio com eucalipto (T4) quando comparada com as plantas que cresceram sem o consórcio (T1).

Figura 2 - Diâmetro ao nível do solo, aos 18 e 30 meses após o plantio, para o grupo das dez espécies florestais, em resposta a quatro estratégias de controle de Urochloa spp., em área de reflorestamento, município de Bom Jardim - RJ. Para cada idade, médias seguidas pela mesma letra, não diferem pelo teste de Tukey $(P \geq 95 \%)$

Figure 2 - Diameter at ground level, at 18 and 30 months after planting, for the group of the ten forest species in response to four Urochloa spp. control strategies in reforestation area, the city of Bom Jardim - RJ state. For each age, averages followed by the same letter do not differ by

Tukey test $(\mathrm{P} \geq 95 \%)$

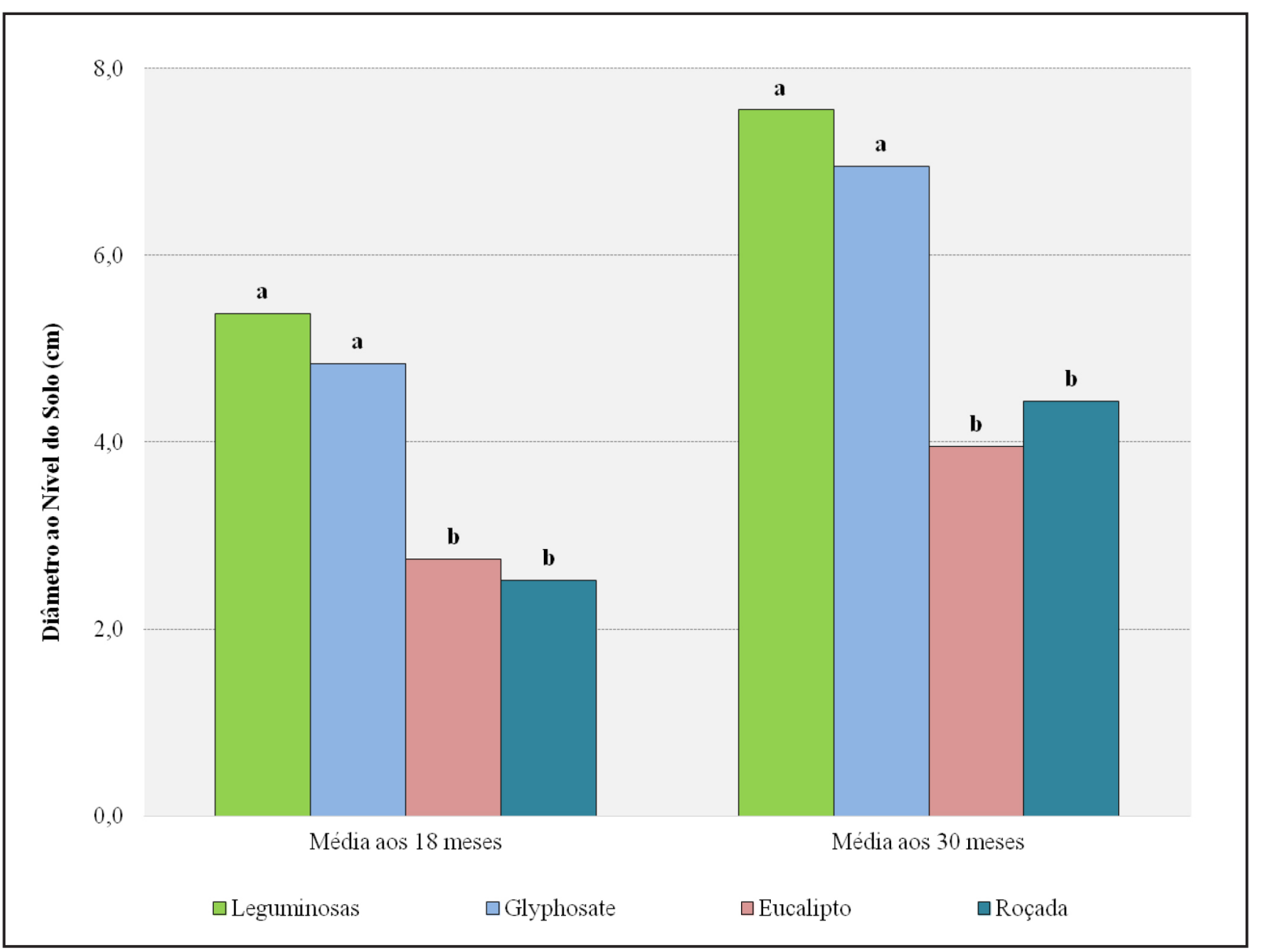

Fonte: Autores (2017) 
Verifica-se pela Tabela 2 que aos 24 e 30 meses após o plantio, os tratamentos consórcio com leguminosas e aplicação de glyphosate apresentaram cobertura de copa significativamente superior aos demais, e sem diferenças significativas entre si.

\section{Tabela 2 - Cobertura do solo pela copa das espécies florestais (\%) calculados pelos métodos do "Grau de cobertura" e "Intercessão de linhas" aos 24 e aos 30 meses após o plantio em área de reflorestamento, município de Bom Jardim - RJ}

Table 2 - Soil cover by the top of forest species (\%) calculated by the methods of "Coverage ratio" and "Intercession of lines" at 24 and 30 months after planting in a reforestation area, the city of Bom Jardim - RJ state

\begin{tabular}{cccccc}
\hline Idade & Método & Leguminosas & Glyphosate & Eucalipto & Roçada \\
\hline \multirow{2}{*}{24 meses } & Grau de cobertura & $91,4 \mathrm{a}$ & $84,1 \mathrm{a}$ & $26,7 \mathrm{~b}$ & $28,0 \mathrm{~b}$ \\
& Intercessão de linhas & $109,0 \mathrm{a}$ & $97,5 \mathrm{a}$ & $54,2 \mathrm{~b}$ & $56,8 \mathrm{~b}$ \\
\hline \multirow{2}{*}{$\mathbf{3}$ meses } & Grau de cobertura & $167,4 \mathrm{a}$ & $143,3 \mathrm{a}$ & $59,4 \mathrm{~b}$ & $61,3 \mathrm{~b}$ \\
& Intercessão de linhas & $150,4 \mathrm{a}$ & $129,5 \mathrm{a}$ & $82,6 \mathrm{~b}$ & $86,0 \mathrm{~b}$ \\
\hline
\end{tabular}

Fonte: Autores (2017)

Em que: Médias seguidas pela mesma letra, na mesma linha, não diferem pelo teste de Tukey ( $\mathrm{P} \geq 95 \%)$.

Aos 24 meses após o plantio, a cobertura por copas no tratamento consórcio com leguminosas era superior a $90 \%$ em área e a $100 \%$ na linha de plantio. Tal constatação indica que grande parte da superfície do solo não está recebendo radiação luminosa direta, devido ao efeito do sombreamento proporcionado pelas copas das plantas florestais, tornando o ambiente progressivamente limitante para as plantas de braquiária.

No tratamento com leguminosas, além da cobertura por copas das espécies florestais, há ainda a cobertura oferecida pelas espécies leguminosas, sobretudo pelo Canavalia ensiformis (feijão-de-porco), mantido na área durante grande parte do tempo. Essa leguminosa apresenta um rápido crescimento, produzindo grande quantidade de biomassa que acaba por recobrir grande parte da superfície do solo (LOPES, 1998), restringindo a oferta de luz ao banco de sementes de plantas daninhas do solo, reduzindo a infestação de braquiária. Resultado semelhante é constatado para a aplicação de glyphosate, em que, aos dois anos após o plantio, a cobertura do solo pela copa das plantas chega a $85 \%$ da área e em quase $100 \%$ na linha de plantio. Além da cobertura das copas das espécies implantadas, é mantida também a cobertura formada pela biomassa seca do capim braquiária, após a ação do herbicida. O rápido recobrimento do solo pelas copas das plantas florestais nesses tratamentos indica que as atividades de manutenção podem ser cessadas antes mesmo dos 24 meses após o plantio, contribuindo para a redução dos custos finais quando adotada as estratégias de controle químico (T2) e de consórcio com leguminosas herbáceas (T3), individualmente ou de forma integrada.

Nos tratamentos com o controle de Urochloa spp. que utilizaram as roçadas nas entrelinhas e capinas nas faixas de plantio (T1 e T4), a cobertura do solo não chegou a 100\% em área até os 30 meses após o plantio. Assim, não é possível caracterizar o estabelecimento dos povoamentos nessas unidades, indicando que as atividades de controle de plantas daninhas não devem ser cessadas. É importante frisar que o sombreamento proporcionado pela copa das plantas de eucalipto nas unidades experimentais do T4 não foi contabilizado nesta análise de cobertura. 
É possível inferir, no entanto, que as plantas de eucalipto contribuem consideravelmente com o sombreamento da superfície do solo nas unidades do T4 (Eucalipto) uma vez que aos 30 meses, as plantas de eucalipto apresentavam maior porte que as nativas, com altura média de $11,9 \mathrm{~m}$ e DAP de $11,4 \mathrm{~cm}$.

O maior crescimento do grupo das dez espécies florestais, tanto em altura (Figura 1) quanto em diâmetro ao nível do solo (Figura 2) e cobertura do solo (Tabela 2) no tratamento de consórcio com leguminosas (T3) e de controle químico (T2) possivelmente também está relacionada com os efeitos físicos, químicos e biológicos proporcionados pela biomassa das leguminosas ou da palhada (mulch) da braquiária.

A biomassa produzida pelas leguminosas e o mulch da braquiária atuam dificultando a chegada de luz na superfície do solo, prejudicando a germinação e o crescimento das plantas infestantes (FERNANDES; BARRETO; EMÍDIO FILHO, 1999; SEVERINO; CHRISTOFFOLETI, 2001). Dentre as espécies de leguminosas com maior potencial, destaca-se o Canavalia ensiformis, que germina rapidamente, tem crescimento simpodial, com uma alta produtividade de fitomassa (LOPES, 1998), dificultando a germinação e o crescimento das plantas de braquiária.

Em relação ao efeito químico, as leguminosas herbáceas normalmente apresentam capacidade de se associarem às bactérias dos gêneros Rhizobium e Bradyrhizobium, eficientes fixadoras do nitrogênio atmosférico (BARRADAS, 2010), contribuindo para uma rápida produção e aporte de biomassa no solo. Silva et al. (2009b) citam ainda o efeito da biomassa das leguminosas sobre a comunidade de plantas daninhas, afetando a sobrevivência e/ou germinação das plantas infestantes através da ação de substâncias alelopáticas liberadas por essas espécies leguminosas. Existem relatos sobre a observação da ação de efeito alelopático de Canavalia ensiformis (MONQUERO et al., 2009) e também de Crotalaria juncea (TIMOSSI et al., 2011), usadas neste estudo.

As leguminosas podem contribuir ainda com efeitos biológicos sob as espécies infestantes, na medida em que contribuem para uma densa e diversificada microbiocenose na superfície do solo, conduzindo à perda de viabilidade das sementes de plantas daninhas (ESPÍNDOLA; GUERRA; ALMEIDA, 1997). Alguns estudos evidenciam o potencial do consórcio de espécies arbóreas nativas com leguminosas herbáceas fixadoras de $\mathrm{N}_{2}$ atmosférico. Santos (2013), realizando seus estudos nas proximidades da área em que foi montado o presente experimento, concluiu que a utilização de espécies leguminosas herbáceas para o controle de plantas de braquiária foi, entre os tratamentos testados, a estratégia que proporcionou o maior crescimento das espécies florestais de restauração. Martins (2011) e César et al. (2013) também avaliaram a eficácia da utilização da cobertura verde como forma de controle de plantas daninhas em povoamento visando a restauração florestal e indicaram que essa forma de controle não foi tão eficaz quanto o controle químico com glyphosate. A maior ou menor eficiência dos métodos depende da maneira como são aplicados. Nos trabalhos de Martins (2011) e César et al. (2013), as espécies de cobertura foram cultivadas por apenas um ciclo, na fase inicial do plantio de restauração, o que possivelmente reduziu os efeitos das leguminosas no controle das plantas infestantes.

Verifica-se pelas Figuras 1 e 2 e Tabela 2 que a aplicação de glyphosate (1,44 kg i.a. $\left.h^{-1}\right)$ proporcionou diferenças significativas de crescimento em comparação com as unidades em que foi realizado o controle convencional (roçada e capina). O rápido estabelecimento dos povoamentos implantados reduz os custos dos projetos de restauração, atual entrave ao ganho de escala dessas ações no Brasil. Entretanto, a utilização do controle químico em projetos e programas de restauração florestal da Mata Atlântica no Brasil é ainda objeto de acalorado debate social. $\mathrm{Na}$ ausência de instrumentos regulatórios, mascarado pelos estigmas do mau manejo desses produtos na agricultura e com inegável efeito benéfico para o rápido crescimento das espécies florestais implantadas, a utilização do controle químico na restauração florestal não é alternativa cogitada em alguns desses projetos. 


\section{Custos de manutenção}

$\mathrm{Na}$ Tabela 3 são apresentadas as quantidades por ano, das atividades de manutenção realizadas para os diferentes tratamentos de controle de Urochloa sp., até 30 meses após o plantio das espécies arbóreas. Não foi incluído o controle de formigas-cortadeiras, pois o mesmo foi realizado em área total, independentemente dos tratamentos.

Tabela 3 - Quantitativo das atividades realizadas para as quatro estratégias de controle de braquiária (Urochloa spp.) em área de reflorestamento, até 30 meses após o plantio, no município de Bom Jardim - RJ

Table 3 - Number of activities done for the four brachiaria control strategies (Urochloa spp.) in reforestation area, up to 30 months after planting in the city of Bom Jardim - RJ state

\begin{tabular}{|c|c|c|c|c|}
\hline \multirow{2}{*}{ Tratamento } & \multirow{2}{*}{ Atividade desenvolvida } & \multicolumn{3}{|c|}{ Ano de intervenção } \\
\hline & & 2012 & 2013 & 2014 \\
\hline \multirow{2}{*}{$\begin{array}{l}\text { T1 } \\
\text { Roçada }\end{array}$} & Roçada nas entrelinhas & 3 & 2 & 2 \\
\hline & Capina das faixas de plantio & 2 & 2 & 1 \\
\hline \multirow{4}{*}{$\begin{array}{l}\text { T2 } \\
\text { Glyphosate }\end{array}$} & Aplicação de glyphosate & 2 & - & - \\
\hline & Capina das faixas de plantio & 1 & - & - \\
\hline & Capina de touceiras de braquiária & 1 & - & - \\
\hline & Roçada de touceiras de braquiária & - & 1 & 1 \\
\hline \multirow{4}{*}{$\begin{array}{l}\text { T3 } \\
\text { Leguminosas }\end{array}$} & Capina em área total e touceiras & 1 & - & - \\
\hline & Semeadura de leguminosas & 4 & 1 & - \\
\hline & Capina de touceiras de braquiária & 3 & 1 & - \\
\hline & Poda do feijão guandu & - & 1 & \\
\hline \multirow{4}{*}{$\begin{array}{l}\text { T4 } \\
\text { Eucalipto }\end{array}$} & Preparo e plantio do eucalipto & 1 & - & - \\
\hline & Coroamento e adubação do eucalipto & 3 & 2 & \\
\hline & Roçada nas entrelinhas & 3 & 2 & 2 \\
\hline & Capina das faixas de plantio & 2 & 2 & 1 \\
\hline
\end{tabular}

Fonte: Autores (2017)

Os tratamentos de consórcio com eucalipto e controle com capinas nas faixas de plantio das espécies nativas e roçadas nas entrelinhas (T4) foram aqueles que demandaram maior quantidade de intervenções de controle, até os 30 meses após o plantio. Isso ocorreu devido às plantas de eucalipto precisarem de maiores cuidados, principalmente na fase inicial após o plantio, quando são mais sensíveis à matocompetição (TAROUCO et al., 2009; LONDERO et al., 2012). Como a maioria das espécies de braquiária estão adaptadas à condição de pastoreio intensivo, suportando cortes sucessivos sem prejuízos para sua sobrevivência (COUGHENOUR, 1985), fica evidente que a roçada é uma operação pouco eficaz para controle dessas plantas, demandando muita mão de obra. 
As atividades relacionadas ao consórcio com leguminosas foram divididas em controle da braquiária e a semeadura de Crotalaria juncea, Canavalia ensiformis e Cajanus cajan. Dessas atividades, a capina em área total para retirada da braquiária e as decorrentes capinas para limpeza de novas touceiras nessa área são as que impactam mais significativamente nos custos de manutenção.

No tratamento de controle com glyphosate, foram feitas apenas duas aplicações de Roundup original $^{\oplus}\left(3,0 \mathrm{~L}\right.$. ha $\left.{ }^{-1}\right)$, aos 2 e 13 meses após o plantio, nas entrelinhas de plantio, e algumas atividades de roçada ou capina foram suficientes para controlar a incidência de novas touceiras isoladas na área.

Como o custo de implantação foi de $\mathrm{R} \$ 6.542,00$ por hectare para todos os tratamentos, foram as atividades de manutenção aquelas que mais contribuíram para a elevação do custo total por hectare. Os valores para capina em faixas e roçada (T1), aplicação de glyphosate (T2), consórcio com leguminosas (T3) e consórcio com eucalipto (T4), foram de R $\$ 7.245,00 /$ ha; $\mathrm{R} \$$ $2.675,00 /$ ha; $R \$ 15.095,00 /$ ha e $R \$ 9.594,00 /$ ha, respectivamente.

Ao considerar o reduzido custo de manutenção e o crescimento proporcionado ao conjunto das espécies florestais, fica atestada a eficácia e a alta eficiência da estratégia de controle pela aplicação de glyphosate. Em comparação a outros métodos de controle de plantas daninhas, o método químico, segundo Silva et al. (2009b), apresenta como vantagem a menor dependência de mão de obra em quantidade. No entanto, a mão de obra deve ser capacitada para o bom manejo do produto, aplicando-o na época adequada, com a tecnologia de aplicação mais indicada. Há ainda muita discussão acerca desse uso, principalmente por possíveis efeitos de contaminação da fauna edáfica ou mesmo de recursos hídricos em áreas ciliares. O presente estudo não contemplou esse objetivo, mas autores como Santos et al. (2011) relatam que os herbicidas à base de glyphosate apresentam baixa toxicidade à mamíferos e aos organismos aquáticos. Além disso, não é facilmente lixiviado, pois é rapidamente adsorvido às partículas do solo, reduzindo riscos de contaminação de águas subterrâneas (AMARANTE JÚNIOR et al., 2002). O tratamento consórcio com leguminosas apresentou o custo mais elevado de manutenção, quase seis vezes superior ao controle com glyphosate e praticamente o dobro do convencional (roçada nas entrelinhas e capina nas faixas de plantio), devido ao baixo rendimento operacional da atividade de capina manual para limpeza em área total, que correspondeu a 38,3\% do custo de controle por esse método.

Também Santos (2013) observou que a capina manual inicial da área corresponde a mais de $30 \%$ do custo do uso desse consórcio em restauração. Mesmo com o maior custo, o consórcio não parece ser uma estratégia inviável, uma vez que há ganho na velocidade de crescimento, o que está diretamente relacionado à redução do tempo de formação do povoamento de restauração, que pode ser atingido antes de 24 meses, pois, nessa época, a cobertura pelas copas era, praticamente, de $100 \%$, conforme mostrado na Tabela 2. Uma das alternativas é que a primeira capina da braquiária, que foi em área total e muito onerosa, seja substituída pela aplicação de glyphosate e depois da dessecação da braquiária seja realizada a semeadura direta da(s) leguminosa(s) em pequenas covetas ou com plantadeiras manuais.

O custo de implantação e de manutenção do eucalipto no tratamento T4 foi incluído como custo de controle de Urochloa spp., o que resultou em aumento do custo de manutenção em 39,3\%, em relação ao não consorciado - controle convencional (T1). A esse custo deverá ser adicionado ainda o custo da colheita da madeira, que deve ocorrer entre 4,5 a 6,0 anos após plantio. Financeiramente a estratégia será viável dependendo do preço dos produtos à base de eucalipto na região, na época da colheita. Em observações de campo, detectou-se que as plantas de eucalipto não foram capazes de reduzir a incidência de braquiária, até os 30 meses após o plantio, em relação às unidades não consorciadas, aumentando os gastos com coroamento e adubação do eucalipto. Da mesma forma, é possível inferir que a integração em pré-plantio com aplicação de glyphosate, poderia contribuir na redução dos custos de manutenção desse consórcio, repercutindo também na maior produção de madeira e, consequentemente, possibilidade de 
maior lucratividade.

Até a idade de 30 meses, os tratamentos de roçada nas entrelinhas e capinas nas faixas (T1) e consórcio de eucalipto (T4) ainda necessitavam de controle do capim braquiária, de tal forma que para estes, o custo de manutenção deve ser ainda mais elevado. Nas unidades de consórcio com leguminosas e naquelas em que fora aplicado glyphosate, já após 18 meses do plantio, não houve mais necessidade de intervenção (Tabela 3).

\section{Conclusões}

Para as condições de realização do trabalho, tanto o consórcio com leguminosas quanto a aplicação de glyphosate se mostraram os métodos mais eficazes para controle de plantas daninhas nas áreas destinadas à restauração florestal. Quando aplicados, os métodos foram eficazes em antecipar o tempo de formação dos povoamentos florestais para menos de dois anos após o plantio, reduzindo os custos com a manutenção dessas áreas. A estratégia mais eficiente, do ponto de vista de economicidade de recursos financeiros, foi o controle químico com o uso do glyphosate, pois além de antecipar o tempo de formação do povoamento de restauração também é o método que apresenta o menor custo de aplicação.

Possivelmente, a integração entre os métodos de controle químico, substituindo a capina manual, seguido do consórcio com leguminosas herbáceas, seja uma estratégia ainda mais eficiente e que precisa ser testada. Estudos complementares devem ser realizados no sentido de identificar e medir as externalidades ambientais inerentes à aplicação do controle químico, sobretudo em zonas ripárias.

O consórcio com eucalipto pode ser uma estratégia viável, visto que não prejudicou o crescimento das espécies nativas utilizadas na restauração florestal. Estudos complementares devem ser realizados com o objetivo de melhorar a produtividade do eucalipto sem retardar o ritmo de crescimento das arbóreas nativas.

\section{Referências}

AMARANTE JÚNIOR, O. P. et al. Glifosato: propriedades, toxicidade, usos e legislação. Química Nova, São Paulo, v. 25, n. 4, p. 589-593, 2002.

AGÊNCIA NACIONAL DE ÁGUAS (Brasil). Hidro Sistema de Informações Hidrológicas. Brasília: Superintendência de Informações Hidrológicas, 2016. Disponível em: www.ana.gov.br. Acesso em: 21 fev. 2016.

BARRADAS, C. A. A. Adubação verde. Niterói: Programa Rio Rural, 2010. 12 p.

BRANCALION, P. H. S. et al.Seletividade dos herbicidas setoxidim, isoxaflutol e bentazon a espécies arbóreas nativas.Pesquisa Agropecuária Brasileira, Brasília, v. 44, n. 3, p. 251-257, 2009.

CANFIELD, R. H. Application of the line interception method in sampling range vegetation. Journal of Forestry, Washington, v. 39, p. 388-394, 1941.

CÉSAR, R. G. et al. Does crotalaria (Crotalaria breviflora) or pumpkin (Cucurbita moschata) interrow cultivation in restoration plantings control invasive grasses? Scientia Agricola, Piracicaba, v. 70, n. 4 , p. 268-273, 2013. 
COUGHENOUR, M. B. Graminoid responses to grazing by large herbivores: adaptations, exaptations, and interacting processes. Annals of the Missouri Botanical Garden, St. Louis, v. 72, p. 852-863, 1985.

ESPÍNDOLA, J. A. A.; GUERRA, J. G.; ALMEIDA, D. L. Adubação verde: estratégia para uma agricultura sustentável. Seropédica: EMBRAPA Agrobiologia, 1997. 20 p.

FERNANDES, M. F.; BARRETO, A. C.; EMÍDIO FILHO, J. Fitomassa de adubos verdes e controle de plantas daninhas em diferentes densidades populacionais de leguminosas. Pesquisa Agropecuária Brasileira, Brasília, DF, v. 34, n. 9, p. 1593-1600, 1999.

GREIG-SMITH, P. Quantitative plant ecology. 2nd ed. London: Butterworths, 1983. 256 p.

LELES, P. S. S.; OLIVEIRA NETO, S. N.; ALONSO, J. M. Restauração florestal em diferentes espaçamentos. In: LELES, P. S. S.; OLIVEIRA NETO, S. N. (ed.). Restauração Florestal e a Bacia do Rio Guandu.Seropédica: Editora Rural, 2015. p. 107-140.

LONDERO, E. K. et al. Influência de diferentes períodos de controle e convivência de plantas daninhas em eucalipto. Cerne, Lavras, v. 18, n. 3, p. 441-447, 2012.

LOPES, O. M. N. L. Feijão-de-porco: leguminosa para adubação verde e cobertura de solo.Acre: Embrapa Amazônia Oriental, 1998. 4 p.

MACHADO, A. F. L. et al.Manejo integrado de plantas daninhas na cultura do eucalipto. In: FERREIRA, R. L. et al. (org.). Manejo integrado de plantas daninhas na cultura do eucalipto. Viçosa, MG: Ed. UFV, 2011. p. 16-38.

MACIEL, C. D. G. et al. Coroamento no controle de plantas daninhas e desenvolvimento inicial de espécies florestais nativas. Semina: Ciências Agrárias, Londrina, v. 32, n. 1, p. 119-128, 2011.

MARTINS, A. F. Controle de gramíneas exóticas invasoras em área de restauração ecológica com plantio total, Floresta Estacional Semidecidual, Itu-SP. 2011. Dissertação de Mestrado (Mestrado em Ciências) - Escola Superior de Agricultura "Luiz de Queiroz”, Piracicaba, 2011.

MELO, A. C. G. et al. Cobertura de copas como indicador de desenvolvimento estrutural de reflorestamentos de restauração de matas ciliares no médio vale do Paranapanema, SP, Brasil. Revista Árvore, Viçosa, MG, v. 31, n. 2, p. 321-328, 2007.

MONQUERO, P. A. et al. Efeito de adubos verdes na supressão de espécies de plantas daninhas. Planta Daninha, Viçosa, MG, v. 27, n. 1, p. 85-95, 2009.

MÜELLER, D.; ELLEMBERG, H. Aims and methods of vegetation ecology. New York: Wiley \& Sons, 1974. 547 p.

NAVE, A. G. et al. Descrição das ações operacionais de restauração. In: RODRIGUES, R. R.; BRANCALION, P. H. S.; IŞERNHAGEN, I. (org.). Pacto pela restauração da Mata Atlântica: Referencial dos conceitos e ações de restauração florestal.São Paulo: LERF; ESALQ,2009.p. 176218.

PITELLI, R. A. Competição e controle das plantas daninhas em áreas agrícolas. Série Técnica IPEF, Piracicaba, v. 4, n. 12, p. 1-24, 1987.

SANTOS, F. A. M. Manejo de Urochloa spp. em povoamento florestal para restauração. 2013. Monografia (Graduação em Engenharia Florestal) - Universidade Federal Rural do Rio de Janeiro, Seropédica, 2013.

SANTOS, L. D. T. et al.Glyphosate em Eucalipto: formas de contato e efeito do herbicida sobre a cultura. In: FERREIRA, R. L. et al. (Org.). Manejo integrado de plantas daninhas na cultura do eucalipto. Viçosa, MG: Ed. UFV, 2011. p. 38-64.

SEVERINO, F. J.; CHISTOFFOLETI, P. J. Efeitos de quantidades de fitomassa de adubos verdes 
na supressão de plantas daninhas. Planta Daninha, Viçosa, MG, v. 19, n. 2, p. 223-228, 2001.

SILVA, A. A. et al. Biologia de plantas daninhas. In: SILVA, A. A.; SILVA, J. F. Tópicos em manejo de plantas daninhas. Viçosa, MG: Ed. UFV, 2009a. p. 1-61.

SILVA, A. A. et al. Métodos de controle de plantas daninhas. In: SILVA, A. A.; SILVA, J. F. Tópicos em manejo de plantas daninhas. Viçosa, MG: Ed. UFV, 2009b. p. 63-81.

SILVA, M. V. Consórcio de espécies nativas com eucalipto para restauração florestal. 2013. Monografia (Graduação em Engenharia Florestal) - Universidade Federal Rural do Rio de Janeiro, Seropédica, 2013.

SOUZA, L. S. et al. Efeito alelopático de plantas daninhas e concentrações de capim-braquiária (Brachiaria decumbens) no desenvolvimento inicial de eucalipto (Eucalyptus grandis.).Planta Daninha, Viçosa, MG, v. 21, n. 3, p. 343-354, 2003.

TAROUCO, C. P. et al. Períodos de interferência de plantas daninhas na fase inicial de crescimento do eucalipto. Pesquisa Agropecuária Brasileira, Brasília, v. 44, n. 9, p. 1131-1137, 2009.

TIMOSSI, P. C. et al. Supressão de plantas daninhas e produção de sementes de crotalária, em função de métodos de semeadura. Pesquisa Agropecuária Tropical, Goiânia, v. 41, n. 4, p. 525530, 2011.

TOLEDO, R. E. B. et al.Efeito de períodos de controle de plantas daninhas sobre o desenvolvimento inicial de plantas de eucalipto. Planta Daninha, Viçosa, MG, v. 18, n. 3, p. 39, 2000. 